\title{
Cultural Effects On Customer Satisfaction With Service Encounters
}

Shirley A. Hopkins, California State University, Chico, USA

Winter Nie, IMD, Chemin de Bellerive 23, Switzerland

Willie E. Hopkins, California State University, Chico, USA

\begin{abstract}
The conceptual model presented in this paper illustrates the relationship that we propose exist between several aspects of culture and customer satisfaction with a service encounter. Specifically, the model proposes that (1) the effectiveness of the service script used during a service encounter is directly related to customer satisfaction with the encounter, (2) cultural differences between the customer and the service employee have an impact on the effectiveness of the service script, and (3) the extent to which the customer identifies with his/her culture moderate the effects that cultural differences have on service script effectiveness. Implications for future research are provided, as are recommendations for managing the relationship.
\end{abstract}

\section{INTRODUCTION}

$\mathrm{t}$ has been noted that because world economies are in or are entering into an era of relatively low unemployment and tight labor markets, countries around the world are finding themselves relying more heavily on imported labor (cf. Kim \& Bhawuk, 2008; Smith, 2007; Sum, Fogg, Khatiwada, Trub'skyy, \& Palma, 2002). Subsequently, the population of countries around the world is becoming more culturally diverse due to immigration, and organizations indigenous to these countries are embracing cultural diversity as a business strategy (cf. Nahavandi, 2003; Pitta, Wood, \& Franzak, 2008; Schaubroeck \& Lam, 2002).

It has been further noted that service organizations are usually the first source of employment for culturally diverse workers, who are immigrating to these countries at an increasing rate (cf. Banks, 2007; Maxwell, McDougall, \& Blair, 2000; Stubor, 2002). For example, one study found that over twenty-two percent of immigrants who arrived in the United States since 1990 worked in service occupations (especially fast food or health care), compared with thirteen percent of native-born U.S. workers (cf. Immigrant Workers..., 2002). When viewed as a composite, these trends virtually ensure that individuals from different cultures will interact as customer and employee within the context of service organizations.

Interactions between customers seeking a particular service and employees assigned to provide the service have been described as a "service encounter" (Chase, Jacobs, \& Aquilano, 2004). Service encounter research (cf. Czepied, Solomon, Surprenant, \& Gutman, 1985; Shostock, 1985; Surprenant \& Solomon, 1987) suggests that the service encounter plays an important role in determining customer satisfaction, especially when the service is characterized by a high degree of person-to-person interaction (Stauss \& Mang, 1999). In many service scenarios, consumers may be limited in their ability to self-select which employee will interact with them during the service encounter. Thus, customers purchasing a particular service may have little choice but to interact with an employee whose culture may be different from their own. In such cases, the use of what are called "service scripts" (Stewart \& Jackson, 2003) is particularly important to achieving a service organization's goal of customer satisfaction.

Within the context of service organizations, a script can be thought of as rules for predicting, interpreting, responding to and controlling a service encounter (cf. Bateson, 2002; Harris, Harris, \& Baron, 2003; O'Connor \& Adams, 1999; Smith \& Houston, 1985). Service script research (c.f. Stewart \& Jackson, 2003) suggests that a script will usually require exchanges between several actors taking on different roles. However, our interest in this paper is on service encounters at the dyadic level (i.e., interaction or exchanges between a single customer and a single 
service employee). It has been suggested that service scripts are particularly important at this level because since the service employee $i s$ the service to the consumer (Surprenant \& Solomon, 1987), customer satisfaction with the service encounter (and thus with the service organization) is likely to depend on how effectively the script is delivered.

Prior research (cf. Fitzsimmons \& Fitzsimmons, 2003; Jones, Moore, Stanaland, \& Wyatt, 1998; Mattila, 1999) further suggests that at the dyadic level of interaction, a service script will be more effective if the customer and the employee providing the service share the same or similar culture. The issue of concern is that if they do not share the same or similar culture, factors (e.g., biases, language, etc.) associated with cultural differences are likely to have effects on the script used to facilitate the service encounter. These effects in turn, will likely have an impact on customer satisfaction with the service encounter.

As the title of this paper implies, our primary objective is to explore the effects of culture on customer satisfaction with service encounters that take place within the context of service organizations. The introductory paragraphs in this paper suggest that the effects of culture on customer satisfaction with service encounters are not necessarily direct, and there may be factors that mediate and moderate these effects. Thus to achieve our primary objective, we offer a conceptual model that illustrates the relationship between these factors. From this model we derive a set of propositions about these relationships that will enhance our understanding of how customer satisfaction with a service encounter is affected by culture.

The conceptual model we present in this paper not only addresses a very timely issue but also provides a framework that service managers in countries around the world might use to better understand and manage the relationship between culture and customer satisfaction with service encounters. Cultural factors that influence customer satisfaction with service encounters have not been fully addressed in the extant service literature. Consequently, practicing service managers have very few resources available to help them formulate strategies designed to ensure customer satisfaction when culture emerges as a factor during a service encounter. If service organizations around the globe are to be successful vis-à-vis increasing cultural diversity in their work force, there is a need for managers of these organizations to possess knowledge of how customer satisfaction might be affected during inter-cultural service encounters. Thus, another objective we pursue in this paper is to add to the existing body of knowledge on this topic; thereby filling in some of the knowledge gaps that service managers might need to formulate appropriate strategies.

We organized this paper into two major sections. In the first major section we present the conceptual model, define (and discuss) its components and their relationship to one another, and then set forth propositions derived from the model. In the second major section we provide integrated discussions and implications for future research and managerial practice.

\section{CONCEPTUAL MODEL AND PROPOSITIONS}

Figure 1

Proposed Relationship

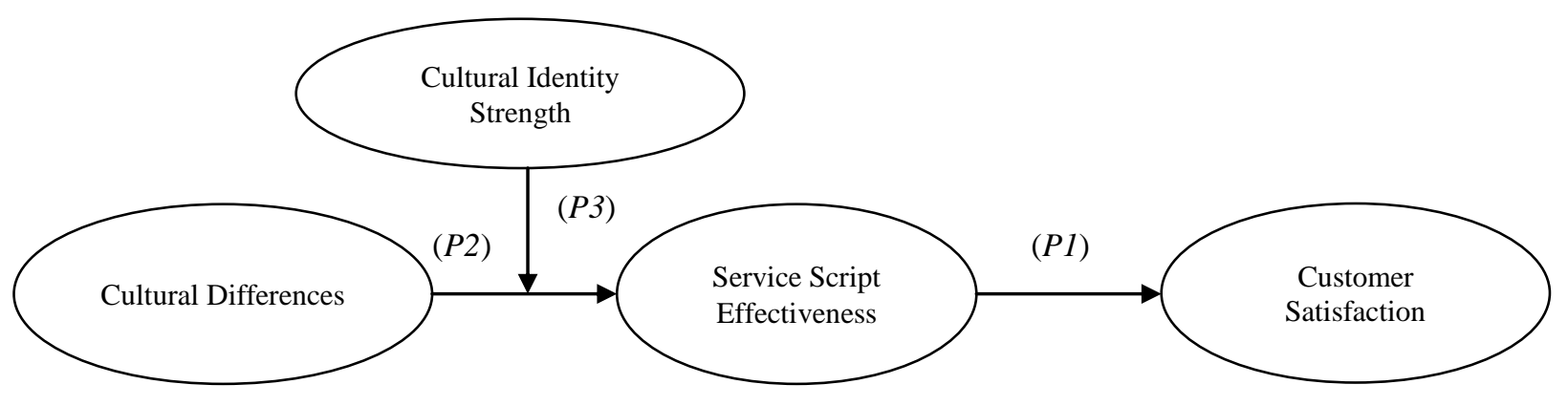


The conceptual model presented in Figure 1 shows the relationships that we propose exist between culture and customer satisfaction with a service encounter. As indicated in the model, it is first proposed that the effectiveness of the service script used during a service encounter is directly related to customer satisfaction with the encounter. We then propose that cultural differences between the customer and the service employee have an impact on the effectiveness of the service script. Finally, it is proposed that the extent to which the customer identifies with his/her culture (cultural identity strength) moderate the effect that cultural differences have on service script effectiveness. In the next few sections of this paper we explore the model and set forth associated propositions.

\section{Service Script Effectiveness and Customer Satisfaction}

A service script is generally defined in the service literature as a written set of scripted actions that prescribe specific steps for handling customer service situations (Solomon et al., 1985) and provide descriptions of commonly held assumptions about what "people think" about the quality of and their satisfaction with circumstances that require social interaction. (cf. Harris et al., 2003; Wierzbicka, 2003). In practice, a service script is commonly used to train service employees to perform routine and recurring tasks in a standardized manner to ensure consistent quality (Alford, 1998). Past research (cf. Mehrabian, 1971; Sheth, 1975) suggest that service scripts not only include dialogues between the customer and the service employee but also include behavioral aspects of social interactions such as communication, body language, and mannerisms.

These studies also suggest that to achieve the goal of customer satisfaction with the service encounter, these behavioral aspects of social interactions must be perceived by the customer as falling within his/her zone of acceptance. In other words, a service script is effective when it helps the customer to clearly interpret these behavioral aspects of the service employee and that interpretation falls within his/her zone of acceptance (Erasmus, Boshoff, \& Rousseau, 2002). Related studies (cf. Hopkins, Hopkins, \& Gross, 2005; Hopkins, Hopkins \& Hoffman, 2005) suggest that behavioral aspects of social interactions are culture-specific, which reinforces the need for service scripts to be effective during an inter-cultural service encounter.

In sum, a service script is used by customers to indicate the precise specification of actions taken and behaviors exhibited by the service employee during a service encounter, and script effectiveness reflect the consumer's mental representation of the satisfaction he/she derives from the service (cf. Abelson, 1981; Bozinoff, 1982; Schurr, 1986). It must be acknowledged here that in some types of service scenarios, service script effectiveness represents one of possibly several factors that determine customer satisfaction with the total service experience. For example, in food services types of organizations customer satisfaction with the total service experience may not only depend on the service encounter but also on the quality of the meal, the manner in which the meal is served, ambiance, etc. However, since the scope of our paper is limited to customer satisfaction with the service encounter, the following proposition seems appropriate:

Proposition 1: There is a direct relationship between service script effectiveness and customer satisfaction with a service encounter

\section{Cultural Differences and Service Script Effectiveness}

The concept of culture is generally defined as any patterned set of behaviors, knowledge, values, beliefs, experiences and traditions shared by a particular group of people (cf. Parhizgar, 2001). This general definition might also apply to the concept of national culture, which refers to the set of values and beliefs shared by people within a nation (cf. Peterson \& Smith, 1997). However, different ethnic groups coexist within nations. For example, Malaysia's population consists of Malays, Chinese, Indians, Arabs, Sinhalese, Eurasions, and Europeans (Malaysia Yearbook, 1996).

Although collectively these groups share the same national culture each group also has its own unique ethnic culture, which includes its own set of learned behaviors, its own language, values, rules for behavior, and traditions (Hofstede, 1983; Naylor, 1998). 
Because the terms culture and national culture can be a source of confusion, our use of the term culture in this paper refers to this latter definition (i.e., ethnic culture). That is, when we use the term culture we are referring to a segment of a larger society (i.e., the global society) whose members are perceived by others in the society as being different in some combination of the following traits: ancestral homeland, language, religion, or race, and members of the segment perceive themselves as culturally distinct within the larger society.

Based on the definition of culture used in this paper, traditionally, cultural differences between groups of people are most often discerned from readily detectable attributes of individuals comprising the groups. For example, physical appearance (e.g., skin color, color and the shape of eyes, texture and color of hair, stature, body structure, etc.) is an observable representation of cultural differences (cf. Alley \& Schutheis, 2001; Boli \& Elliott, 2008; Ferguson, Rhodes, \& Lee, 2001; Ferraro \& Cummings, 2007; Levin, 2000; Sporer, 2001). The physical appearance of a customer from tribal Africa and the physical appearance of a service employee from China, for instance, is an observable indication that cultural differences exist between them.

Inferring from the work of Milliken and Martin (1996), a general proposition set forth is that cultural differences (particularly observable differences) play an important role in shaping a customer's perception of service script effectiveness during a service encounter. That is, physical appearance may provide a visual cue to the customer that she/he shares the same or similar culture as the service employee. In such cases, culture is likely to be a non-factor and factors other than culture (e.g., personality) may affect customer perceptions of service script effectiveness. On the other hand, physical appearance may provide a visual cue to the customer that she/he does not share the same culture as the service employee and that additional cultural differences (e.g., language) are likely to exist between her/him and the service employee; differences that will possibly make the customer's experience with the service encounter (facilitated by the service script) fall outside of his/her zone of acceptance.

For example, since language proficiency often is presumed to be an indicator of competence (Fernandez, 1991) it has implications for service script effectiveness from a communications perspective. When cultural differences exist, the customer's language is not likely the native language of the service employee's. Trandis (1994) contends that communication between individuals whose native language differs multiplies the chances that ineffective communication will occur. Moreover, as suggested by Beamer (1992), even if the service employee is proficient in the customer's native language, linguistic ability does not necessarily assume communication competence. For instance, the service employee may not understand the nuances of the customer's native language and will likely speak it with an accent, and accents present barriers to effective intercultural communication (Chaney \& Martin, 2000) and thus to service script effectiveness.

In addition to exhibiting language/communication competence, the service employee must also behave in a manner consistent with the customer's expectations concerning non-verbal aspects of the service script. In other words, it is not only what is said while delivering the script that matters but also the manner in which it is said. For example, factors such as kinesics (e.g., body language), oculesics (e.g., the use of the eyes, symbolizing the extent to which the service employee is paying attention), proxemics (e.g., the way in which the service employee structures the space around him or her), and paralanguage (e.g., voice volume, speed of talking, amount of silence, avoidance of silence) may be cultural differences that impact script effectiveness (Dahl, 1998). Based on this theoretical support, the following propositions seem appropriate:

Proposition 2a: The greater the perceived or real cultural differences that exist between the customer and the service employee, the greater will be the impact of these differences on service script effectiveness

Proposition 2b: The service script will be more effective when perceived or real cultural differences between the customer and the service employee are small

Proposition 2c: The service script will be less effective when perceived or real cultural differences between the customer and the service employee are large 


\section{The Cultural Identity Strength Moderator}

The concept of cultural identity strength is defined in this paper as the extent to which the customer identifies with his/her culture. This definition is derived from social identity theory (Tajfel \& Turner, 1979), where the focus is on inter-group relations. One component of social identity theory that is relevant to our model is identification. For purposes of this paper, an operational definition of this component is that the customer identifies with a particular cultural group and, because of observable cultural differences, the customer perceives that the service employee identifies with a different cultural group. Another component of social identity theory is categorization. For purposes of this paper, categorization refers to the tendency for the customer (who identifies with a particular cultural group) to place the service employee (who the customer perceives as identifying with another cultural group) into a self-defined category with attributes that may evoke positive or negative affective behaviors from the customer.

Our operational definition of these components of social identity theory are consistent with research conducted by Milliken and Martins (1996), who suggest that categorizing individuals based on observable differences (identification) is likely to evoke responses that are due directly to biases, prejudices, or stereotypes. However, other research (cf. Akerlof \& Kranton, 2005; Fisher, Doughty, \& Mussayeva, 2008; Hogg \& Terry, 2000; Hopkins \& Hopkins, 2002; Sulman, Kanee, \& Savage, 2007) suggest that the extent to which individuals identify with their respective culture determines the nature of such responses. In other words, drawing from selfcategorization theory research (cf. Turner, Hogg, Oakes, Reicher, \& Wetherell, 1997), if culture is not salient to an individual's self worth or distinctiveness (weak cultural identity) the responses may not necessarily be negative.

The overarching message to be distilled from studies cited in this section of our paper is that observable cultural differences represent identification cues that can elicit categorization behaviors on the part of the customer; behaviors that can evoke positive or negative responses. If the customer identifies strongly with his/her culture we might expect such responses to be stronger (and based on biases, prejudices, or stereotypes) than when the customer does not identify strongly with his/her culture. The underlying message to be distilled is that if the customer does not identify strongly with his/her culture, then the cultural differences (e.g., physical appearance, language, demeanor) that play an important role in shaping a customer's perceptions of service script effectiveness are likely to be less of a factor or a non-factor during a service encounter. Based on this theory-supported logic, it seems reasonable to propose that the magnitude of the effects that cultural differences might have on service script effectiveness depend on the extent to which the customer identifies with his/her culture. Thus, the following propositions seem appropriate:

Proposition 3a: Cultural identity strength moderates the effects of cultural differences on service script effectiveness

Proposition 3b: When the customer does not identify strongly with her/his culture, the effects of cultural differences on service script effectiveness will be less than when the customer identifies strongly with her/his culture

\section{ISSUES AND IMPLICATIONS}

As mentioned in the introduction section of this paper, during a service encounter the service employee is the service to the consumer (Surprenant \& Solomon, 1987). Subsequently, customer satisfaction depends on the quality of the dyadic interactions that occur during the service encounter; where the quality of the dyadic interactions is a function of how effectively the service script is executed. As suggested in our conceptual model, there is a potential for service script effectiveness to be compromised when the customer and service employee are from different cultures. However, our model also suggests that cultural identity strength plays a major role in determining the extent to which service script effectiveness is compromised and thus the extent to which the goal of customer satisfaction is achieved.

Developed through systematic analyses, the theory-supported relationships described in the model not only contributes to our understanding of the process by which culture affects customer satisfaction with a service 
encounter but also makes a contribution to the service literature by building on the extant research related to service scripts and service encounters. Specifically, the conceptual model and the propositions derived from it provide a framework for understanding the conditions under which culture is most likely to affect customer satisfaction with a service encounter. However, there is still much work to be done. In the next couple of sections we provide directions for future research, mostly in the form of questions to be answered, and discuss implications for managerial practice as it relates to the culture-customer satisfaction relationship. Finally, we provide some concluding remarks that reinforce the importance of this topic.

\section{Implications for Future Research}

As future researchers conduct follow up theoretical or empirical studies of our conceptual model, there are several questions that might be placed on their research agenda. Since culture is an important construct in our model, one such question might be the following: With respect to its effect on customer satisfaction, what is the nature of the ethnic culture-national culture interface during a service encounter? The context for providing an answer to this question might be a situation where a Chinese customer from Hong Kong has a service encounter with a service employee who has recently immigrated to Hong Kong from mainland China. Since Hong Kong Chinese have long been exposed to British and American national cultures over the years, more so than the more homogeneous culture of mainland China, their identification with ethnic Chinese culture is not likely to be as strong as their mainland counterparts.

Perhaps one of the first issues to be resolved concerns whether or not this situation (i.e., the interface of national and ethnic culture) can be considered an inter-cultural service encounter. In this particular situation, cultural differences based on physical appearance, language, and demeanor will likely be very small. In this case, perhaps knowledge that the service employee is from "another culture" represents a cue that evokes categorization behaviors. If the customer does possess this knowledge, a question raised might be: Will the outcome of the service encounter be influenced by the moderating effects of cultural identity strength or simply a function of customer bias against or for the service employee from mainline China? What if the customer does not possess this knowledge? What implications might this have for our model?

Continuing this line of questioning, what if a particular customer has had prior service encounters with service employees from several different cultures and some were positive and some were negative? Would the moderating effects of cultural identity strength be culture-specific and limited to service employees from cultures with which the customer has had unilateral positive/negative experiences? These are representative of the types of questions that future researchers might want to answer as they go about the task of providing practicing service managers with information that will help them to better understand and manage the culture-customer satisfaction relationship.

\section{Implications for Managerial Practice}

Culture is the variable of interest in our conceptual model, and the various literatures cited in this paper support the existence of a strong relationship between this variable and customer satisfaction with a service encounter. While our model implicitly places the burden of achieving the customer satisfaction goal on the service employee, expecting that she/he has the requisite skills to overcome any cultural differences barriers that may interfere with service script effectiveness, the service organization and the customer also play prominent roles in achieving this goal.

Since culture is proposed to be a major determinant of customer satisfaction, albeit indirect through the service script mediator, another goal managers of service organizations might seek to achieve is that of suppressing the salience of culture, unless culture is mission critical. In other words, if strategies designed to weaken or reduce the strength of perceptions of cultural differences and in-group/out-group sentiments (i.e., cultural identity factors) were implemented to support inter-cultural service encounters, service script effectiveness and thus customer satisfaction are likely to be enhanced. We propose that interdependent strategies associated with the customer, the service employee, and the service organization might be used to achieve this goal. These strategies are shown in Figure 2. 
Figure 2

Inter-Cultural Service Encounter Strategies

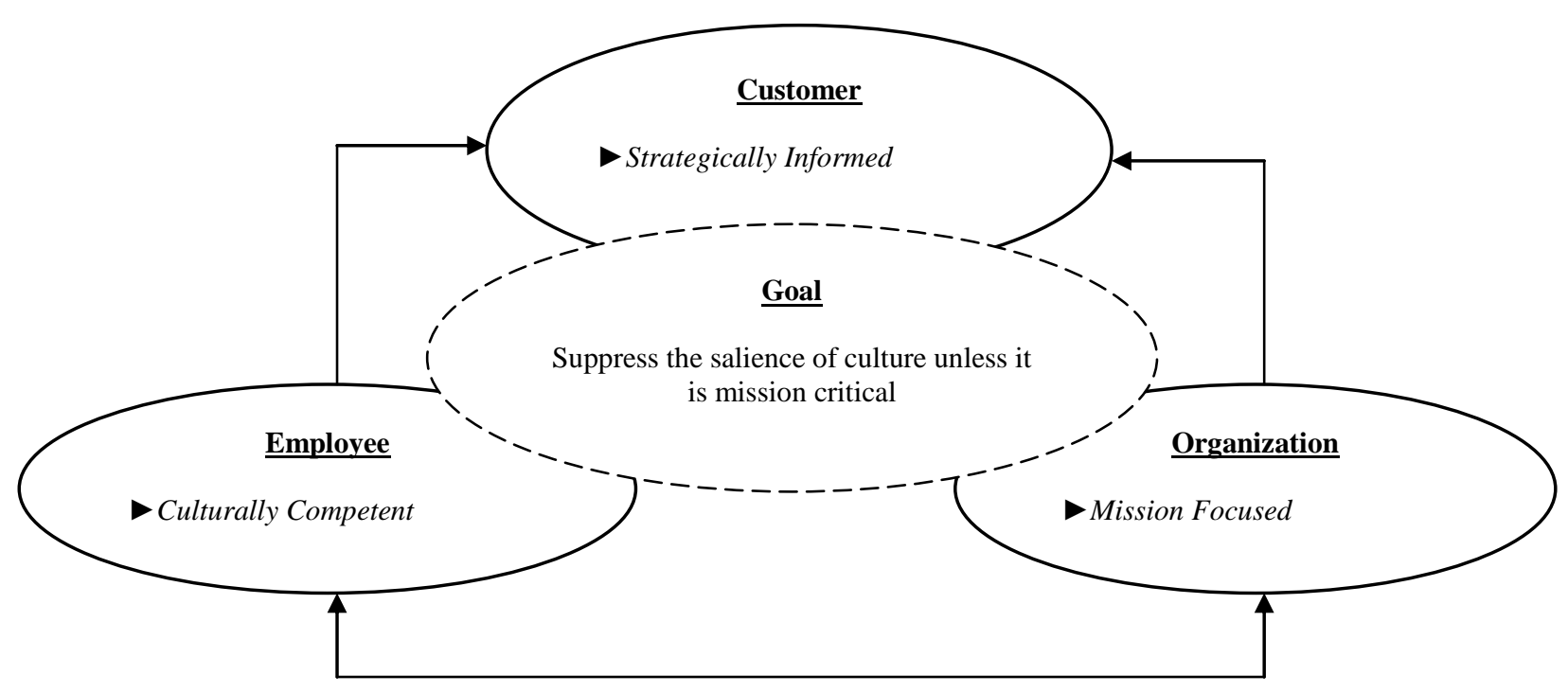

As indicated in the model, the goal is to suppress the salience of culture, unless it is mission critical. As an example of what we mean by mission critical, consider a situation where the name of the service organization is, say, Dos Amigos Mexican Restaurant. In this particular situation, culture (in this case Mexican culture) would be mission critical and customer service would be designed around meeting the needs of customers who most likely have a clear understanding that the cultural theme of the organization will be part of their service encounter experience. If culture is not mission critical, and the customer may become a participant in an inter-cultural service encounter outside the context of a service organization with a particular cultural theme, the suppression of culture would be the goal to achieve.

The rationale is that by doing so, attention is drawn away those cultural difference factors (e.g., physical appearance, language, demeanor, etc.) that may interfere with service script effectiveness. Less interference, as proposed in the Figure 1 model, is associated with greater customer satisfaction with the service encounter. The model (Figure 2) also suggests that strategies for achieving this goal include a strategically informed customer, a culturally competent service employee, and a mission focused service organization. In the following few sections of this paper we discuss the content of these strategies under conditions where culture is not critical to the organization's mission or an integral part of its service mix, but the occurrence of inter-cultural service encounters is frequent.

The Strategically Informed Customer: In a perfect situation, the extent to which a customer identifies with his/her culture would be known and adjustments could be made such that the outcome of the service encounter would be more predictable. For example, managers of service organizations might be able to match the customer with a service employee with whom the customer shares the same culture or with a service employee whose physical features are similar to the customer's such that cultural differences are not readily apparent. In the absence of this perfect knowledge, and thus the service manager's inability to make the appropriate adjustments, it is possible that observable cultural differences (especially when culture is salient) may evoke customer bias at the outset of a service encounter. The saliency of culture may become more of a factor if other cultural differences (e.g., language, demeanor, etc.) come into play during the service encounter. As suggested in Figure 2, the effects of these dimensions of culture on service script effectiveness are likely to be suppressed during a service encounter if the customer is strategically informed. 
Our definition of a strategically informed customer is one whose expectations have been shaped, such that the customer is aware of what he/she is likely to experience as a patron of the organization and as a participant in the service encounters that take place within the organization. In terms of content, the customer might be strategically informed that the organization's total service mix includes sensitivity to cultural issues from customer, employee, and organizational perspectives. This strategic information might be transmitted to the customer in the form of mission statement wording, website messages, advertising, symbolic messaging on the premises, marketing materials, etc. While this information may shape the customer's expectations and divert attention away from cultural differences that affect service script effectiveness, it must be reinforced by a culturally competent service employee.

The Culturally Competent Employee: It has been suggested that one of the reasons culture becomes salient during a service encounter is because actors (e.g., customer and service employee) from different cultures have different understandings regarding the interaction process and different styles of dialogue (Korac-Kakabadse, Kouzmin, Korac-Kakabadse, \& Savery, 2001). The implication is that if at least one of the actors possesses an understanding, culture would not be as salient. Further implied is that a culturally competent service employee would possess this understanding.

Cross, Bazron, Dennis, and Isaacs (1989) suggests that being culturally competent means that the service employee accepts and has respect for cultural differences, pays attention to the dynamics of those differences, conducts periodic self-assessment on him/herself regarding culture, develops cultural knowledge on an ongoing basis, and has the resources and flexibility with service models to meet the needs of culturally different customers. The bi-directional arrow in Figure 2 indicates that it is incumbent on the service organization to ensure that the service employee is culturally competent, either through the hiring process or through development (i.e., cultural diversity training).

The Mission Focused Organization: The content of a recent article (Robinowitz, 2008) suggests that being mission focused includes the following six key elements: (1) aligning services with the organization's mission, (2) developing and maintaining a customer-service culture, (3) using data-driven strategies, (4) dialogue and engagement, (5) organizational adaptability and alliance building, and (6) using the CEO as a broker of ideas. As indicated by the arrows in the model shown in Figure 2, these elements of being mission focused relates not only to the organization but to the customer and the service employee as well.

For example, the first element implies that the organization must first have a clear mission, understand what that mission means, and then align it with the services being offered. The second element suggests that the organization must know its customer base, its needs, and how to meet those needs. Those needs might include feeling comfortable (suppressed cultural saliency) interacting with a service employee from a culture that is different from the customer's. The third and fourth elements have implications for ways in which the service manager might ensure that the customer is strategically informed (e.g., gathering customer-related data through dialogue and engagement and using those data to design marketing messages, mission statement content, etc.).

We interpret the fifth and sixth elements as directives to senior executives to routinely monitor the service organization's customer base for cultural shifts, and adjust the service mix (e.g., periodically updating the cultural competencies and skills of service employees, developing more effective ways to build customer alliances/loyalty using strategic information strategies, etc.) as appropriate. Relating these elements to the strategies listed in Figure 2 (i.e., strategically informing the customer, having culturally competent service employees, and being mission focused) provides an integrative view of how the goal of suppressing cultural saliency is likely to be achieve then these strategies are implemented. With this goal achieved, service scripts will be more effective in achieving the overarching goal of customer satisfaction.

\section{Concluding Remarks}

In a study conducted by Sum et al. (2002), it was found that approximately six out of every ten new immigrants to the United States are employed by service and service-related sectors of the U.S. economy. Similar to the U.S. experience, a large percentage of what is called the "global work force" (Johnston, 1991), or workers from a variety of different cultures that are finding employment in countries other than their own, is being employed by 
service and service-related sectors of their host country's economy (cf. Maxwell et al., 2000). The major implication is that as service organizations in host countries hire more and more service employees who do not share the same culture as their host country customers, the incidence of inter-cultural service encounters and the attendant issues will increase. That is, if culture is a salient issue, the complexity that cultural differences bring to these encounters may interfere with the service scripts that play a significant role in determining customer satisfaction with the encounter and perhaps the total service experience.

The model set forth in this paper not only provides a conceptual framework for understanding the relationship between culture and customer satisfaction, but also suggests the process by which this relationship might be managed such that the outcome of an inter-cultural service encounter is consistent with customer expectations and organizational goals. As suggested, managing this process entails the implementation of strategies designed to suppress the saliency of culture if it interferes with desired outcomes. Finally, the overarching message we hope to be conveyed by our paper is that the relationship between culture and customer satisfaction with a service encounter is important to the success of service organizations and can be effectively managed if properly understood. The model presented in this paper will hopefully facilitate better understanding of this relationship.

\section{REFERENCES}

1. Abelson, R.P. (1981) 'Psychological status of the script concept', American Psychologist, 36: 715-729.

2. Alford, B. L. (1998) Using cognitive scripts to assess the process of professional service delivery. Journal of Professional Services Marketing, 16: 77-103.

3. Alley, T.R., \& Schutheis, J.A. (2001) 'Is facial skin tone sufficient to produce a cross-racial identification effect?', Perceptual and Motor Skills, 92: 1191-1198.

4. Banks, J.A. (2007) Diversity and citizenship education: Global perspectives. Indianapolis, IN: Jossey-Bass.

5. Bateson, J. (2002) 'Consumer performance and quality in services', Managing Service Quality, 12: 206209.

6. Beamer, L. (1992) 'Learning intercultural communication competence', The Journal of Business Communication, 29: 285-303.

7. Boli, J., \& Elliott, M.A. (2008) Facade Diversity: The Individualization of Cultural Difference. International Sociology, 23: 540-560.

Bozinoff, L. (1982) 'A script theoretic approach to information processing: an energy conservation application', Advances in Consumer Research, vol. 9: 481-486.

8. Chaney, L.H., \& Martin, J.S. (2000) Intercultural business communication, Upper Saddle River, NJ: Prentice Hall.

9. Chase, R.B., Jacobs, F.R., \& Aquilano, N.J. (2004) Operations management for competitive advantage. Boston: McGraw-Hill.

10. Cross, T., Bazron, B., Dennis, K. \& Isaacs, M. (1989) Towards a culturally competent system of care: A Monograph on Effective Services for Minority Children Who Are Severely Emotionally Disturbed: Volume I Washington, DC: Georgetown University Child Development Center.

11. Czepiel, J.A., Solomon, M.R., Surprenant, C.F., \& Gutman, E.G. (1985) 'Service encounters: An overview', In Czepiel, J.A., Solomon, M.R., \& Surprenant, C.F. (Eds.), The service encounter: Managing employee/customer interaction in service businesses: 3-15. Lexington, MA: Lexington Books.

12. Dahl, S. (1998) Communications and culture transformation: Cultural diversity, globalization and cultural convergence. Project presented to the European University, Barcelona. University of Luton, UK.

13. Erasmus, A.C., Boshoff, E. \& Rousseau, G.G. (2002) 'The potential of using script theory in consumer behavior research', Journal of Family Ecology and Consumer Sciences, 30: 1-9.

14. Fernandez, J.P. (1991) Managing a diverse work force: Regaining the competitive edge. Lexington, MA: Lexington Books.

15. Fitzsimmons, J.A., \& Fitzsimmons, M.J. (2003) Service management: Operations, strategy, and information technology. Boston: McGraw-Hill.

16. Ferguson, D.P., Rhodes, G., \& Lee, K. (2001) 'They all look alike to me: Prejudice and cross-face recognition', British Journal of Psychology, 92: 567-577.

17. Ferraro, P.J., \& Cummings, R.G. (2007) Cultural diversity, discrimination, and economic outcomes: An experimental analysis. Economic Inquiry, 45: 217-232. 
18. Fisher, C., Doughty, D., \& Mussayeva, S. (2008) Learning and Tensions in Managerial Intercultural Encounters: A Dialectical Interpretation. Management Learning, 39: 311-327.

19. Harris, R., Harris, K., \& Baron, S. (2003) 'Theatrical service experiences: Dramatic script development with employees', International Journal of Service Industry Management, 14: 184-199.

20. Hofstede, G. (1983) 'The cultural relativity of organizational practices and theories', Journal of International Business Studies, 14: 75-89.

21. Hogg, M.A., \& Terry, D.J. (2000) 'Social identity and self-categorization processes in organizational contexts', Academy of Management Review, 25: 121-140.

22. Hopkins, W. E., \& Hopkins, S. A. (2002). 'Effects of cultural recomposition on group interaction processes', Academy of Management Review, 27, 541-553.

23. Hopkins, W.E., Hopkins, S.A., \& Gross, M. (2005). 'Recomposition type and monoculture group effectiveness', Journal of Organizational Behavior, 26: 949-965.

24. Hopkins, S.A., Hopkins, W.E., \& Hoffman, D. (2005) 'Domestic inter-cultural service encounters: An integrated model', Managing Service Quality, 15: 329-343.

25. Immigrant workers and the great American job machine: The contributions of new foreign immigration to national and regional labor force growth in the 1990s. 2002. Center for Labor Market Studies, Northeastern University.

26. Johnston, W.B. (1991) Global Work Force 2000. Harvard Business Review, 69: 115-127

27. Jones, E., Moore J. N., Stanaland A. J. S. \& Wyatt R. A. J. (1998) Salesperson race and gender and the access and legitimacy paradigm: Does difference make a difference? Journal of Personal Selling and Sales Management, 18: 71-88.

28. Kanousi, A. (2005) An empirical investigation of the role of culture on service recovery Expectations. Managing Service Quality, 15: 57-69.

29. Kayis, B., Kim, H., \& Shin, T.H. (2003) A comparative analysis of cultural, conceptual and practical constraints on quality management implementations: Findings from Australian and Korean banking industries. TQM \& Business Excellence, 14: 765-777.

30. Kim, Y.Y., \& Bhawuk, D.P.S. (2008) Globalization and diversity: Contributions from intercultural research. International Journal of Intercultural Relations, 32: 301-304.

31. Korac-Kakabadse N., Kouzmin A., Korac-Kakabadse A., \& Savery L. (2001) Low- and high-context communication patterns: towards mapping cross-cultural encounters. Cross Cultural Management, 8: 3-24

32. Lee, M.S. (2008) The global rule: Secrets of selling to multicultural customers. Dublin, CA: EthnoConnect.

33. Levin, D.T. (2000) Race as a visual feature: Using visual search and perceptual discrimination tasks to understand face categories and the cross-race recognition deficit. Journal of Experimental Psychology, 129: 559-574.

34. Lorenzoni, N., \& Lewis, B.R. (2004) Service recovery in the airline industry: a cross-cultural comparison of the attitudes and behaviours of British and Italian front-line personnel. Managing Service Quality, 14: $11-25$.

35. Malaysia Yearbook. 1996. Kuala Lumpur: Berita Publishing.

36. Mattila, A.S. (1999) The role of culture in the service evaluation process. Journal of Service Research, 1: 250-261.

37. Maxwell, G., McDougall, M., \& Blair, S. (2000) Managing diversity in the hotel sector: The emergence of a service quality opportunity. Managing Service Quality, 10: 367-373

38. Mehrabian, A. (1971) Silent Messages. Belmont, CA: Wadsworth.

39. Milliken, F. J., \& Martins, L. L. (1996) Searching for common threads: Understanding the multiple effects of diversity in organizational groups. Academy of Management Review, 21: 402-433.

40. Nahavandi, A. (2003) The art and science of leadership. Upper Saddle River, NJ: Prentice Hall.

41. Naylor, L.L. (1998) American culture: Myth and reality of a culture of diversity. Westport, Conn: Bergin \& Garvey.

42. O'Connor, K.M., \& Adams, A.A. (1999) What novices think about negotiation: A content analysis of scripts. Negotiation Journal, 15: 135-147.

43. Parhizgar, K.D. (2001) Multicultural behavior and global business environments. Binghamton, NY: International Business Press.

44. Peterson, M. F., \& Smith, P. B. (1997) Does national culture of ambient temperature explain cross-national differences in role stress? No sweat! Academy of Management Journal, 40(4): 930-946. 
45. Pitta, D.A., Wood, V.R., \& Franzak, F.J. (2008) Nurturing an effective creative culture within a marketing organization. Journal of Consumer Marketing, 25: 137-148.

46. Robinowitz, C. (2008) We're getting stronger, more mission focused. Psychiatric News, 43: 3

47. Schank, R., \& Abelson, R. (1977) Scripts, plans, goals and understanding. New Jersey: Lawrence Erlbaum.

48. Schaubroeck, J. \& Lam, S.S.K. (2002) How similarity to peers and supervisor influences organizational advancement in different cultures. Academy of Management Journal, 45: 11-20.

49. Schurr, P.H. 1(986) Four script studies: What we have learnt. Advances in Consumer Research, 13: 498503.

50. Shaw-Ching Liu, B., Furrer, O., \& Sudharshan, D. (2001) The relationships between culture and behavioral intentions toward services. Journal of Service Research, 4: 118-129.

51. Sheth, J.N. (1975) Buyer-Seller interaction. Six Annual Conference Proceedings, Association for Consumer Research, 382-386.

52. Shostack, L. (1985) Planning the service encounter. In Czepiel, J.A., Solomon, M.R., \& Surprenant, C.F. (Eds.), The service encounter: Managing employee/customer interaction in service businesses: 243-254. Lexington, MA: Lexington Books.

53. Smith, R.C. 2007. The UNESCO convention on the protection and promotion of the diversity of cultural expressions: Building a new world information and communication order? International Journal of Communication, 1: 24-55.

54. Smith, R.A., \& Houston, M.J. (1985) A psychometric assessment of measures of scripts in consumer memory. Journal of Consumer Research, 12: 214-224.

55. Solomon, M. R., C. Surprenant, J.A. Czepiel, \& E.G. Gutman (1985) A role theory perspective on dyadic interactions: The service encounter. Journal of Marketing, 49: 99-111.

56. Sporer, S.L. (2001) Eyewitness identification: Recognizing faces of other ethnic groups: and integration of theories. Psychology, Public Policy and Law, 7: 1-45.

57. Stauss, B., \& Mang, P. (1999) Culture shocks in inter-cultural service encounters? Journal of Services Marketing, 13: 329-346.

58. Stewart, D.M. \& E.C. Jackson (2003) Matching Customer Scripts and Service Encounter Designs. Proceedings of the Decision Sciences Institute National Conference.

59. Stubor, M. (2002) Corporate best practice: What some European organizations are doing well to manage culture and diversity. In G. Simmons (Ed.), Eurodiversity: A business guide to managing difference. London: Butterworth-Heinemann.

60. Sum, A., Fogg, N., Khatiwada, I., Trub'skyy, M., \& Palma, S. (2002) Immigrant workers and the great American job machine: The contributions of new foreign immigration to national and regional labor force growth in the 1990s. Center for Labor Market Studies, Northeastern University.

61. Sulman, J., Kanee, M., \& Savage, D. (2007) Does Difference Matter? Diversity and Human Rights in a Hospital Workplace. The Journal of Health Care Social Work, 44: 145-159.

62. Surprenant, C.F., \& Solomon, M.R. (1987) Predictability and personalization in the service encounter. Journal of Marketing, 51: 86-96.

63. Tajfel, H. (1981) Human groups and social categories. London: Cambridge University Press.

64. Tajfel, H., \& Turner, J.C. (1979) An integrative theory of intergroup conflict. In W. G. Austin \& S. Worchel ( Eds.), The social psychology of intergroup relations: 33-47. Monterey, CA: Brooks-Cole.

65. Triandis, H.C. (1994) Culture and social behavior. New York: McGraw-Hill.

66. Turner, J.C. (1982) Towards a cognitive redefinition of the social group. In H. Tajfel (Ed.), Social identity and intergroup relations: 15-40. Cambridge: Cambridge University Press.

67. Turner, J. C., Hogg, M. A., Oakes, P. J., Reicher, S. D., \& Wetherell, M. (1987). Rediscovering the social group: A self-categorization theory. Oxford, England: Basil Blackwell.

68. Wierzbicka, A. (2003) Cross-cultural pragmatics: The semantics of human interaction. Berlin: Mouton de Gruyter. 


\section{NOTES}

